\title{
Risk factors for recurrent hospital-acquired Clostridium difficile infection in a Japanese university hospital
}

This article was published in the following Dove Press journal:

Clinical and Experimental Gastroenterology

14 July 2015

Number of times this article has been viewed

\section{Mayu Hikone' \\ Yusuke Ainoda ${ }^{1,2}$ \\ Sayaka Tago 2 \\ Takahiro Fujita ${ }^{2}$ \\ Yuji Hirai ${ }^{2}$ \\ Kaori Takeuchi ${ }^{2}$ \\ Kyoichi Totsuka ${ }^{3}$}

'Department of Infectious Diseases, Tokyo Metropolitan Bokutoh General Hospital, ${ }^{2}$ Department of Infectious Diseases, Tokyo Women's Medical University, ${ }^{3}$ Department of Internal Medicine, Kitatama Hospital, Tokyo, Japan
Correspondence: Yusuke Ainoda Department of Infectious Diseases, Tokyo Women's Medical University, 8-I, Kawada-cho, Shinjuku-ku,

Tokyo 162-8666, Japan

Tel +813335381 II

Fax +81333588995

Email ainoda.yusuke@twmu.ac.jp
Background: Clostridium difficile infection (CDI) is a highly prevalent hospital-associated infection. Although most patients respond well to discontinuation of antibiotics, $20 \%-30 \%$ of patients relapse. To initiate early therapeutic measures, the risk factors for recurrent CDI must be identified, although very few Japanese studies have used standard surveillance definitions to identify these risk factors.

Methods: We retrospectively reviewed the medical records of patients with health care facilityonset CDI between August 2011 and September 2013. Patients with diarrhea who were positive for Clostridium difficile (via an enzyme immunoassay) were defined as having CDI. Clinical data (eg, demographics, comorbidities, medication, laboratory results, and clinical outcomes) were evaluated, and multivariate analysis was used to identify risk factors that were associated with recurrent CDI.

Results: Seventy-six health care facility-onset CDI cases were identified, with an incidence rate of 0.8 cases per 10,000 patient-days. Fourteen cases $(18.4 \%)$ were recurrent, with 13 patients having experienced a single recurrent episode and one patient having experienced three recurrent episodes. The 30-day and 90-day mortality rates were $7.9 \%$ and $14.5 \%$, respectively. Multivariate analysis revealed that recurrent patients were more likely to have underlying malignant disease (odds ratio: $7.98 ; 95 \%$ confidence interval: $1.22-52.2 ; P=0.03$ ) and a history of intensive care unit hospitalization (odds ratio: 49.9; 95\% confidence interval: $1.01-2,470 ; P=0.049$ ).

Conclusion: Intensive care unit hospitalization and malignancy are risk factors for recurrent CDI. Patients with these factors should be carefully monitored for recurrence and provided with appropriate antimicrobial stewardship.

Keywords: Clostridium difficile, recurrent infection, risk factors

\section{Introduction}

Clostridium difficile (CD) is a spore-forming anaerobe, and the toxin-producing strain is known to cause Clostridium difficile infection (CDI), which is one of the most prevalent of the health care-associated infections. CDI is characterized by symptoms such as diarrhea, fever, and enteric pain, ${ }^{1}$ and severe CDI can be fatal in patients with hypotension, renal failure, sepsis, colic ileus, and toxic megacolon. ${ }^{2}$ The diagnosis of CDI is based on the clinical manifestation and laboratory test results, which include testing the stool sample for CD toxin, stool cultures, and polymerase chain reaction testing. ${ }^{3}$ Furthermore, CDI is clinically important, as CD can be transmitted personto-person, especially in health care facilities, and can cause nosocomial outbreaks. Therefore, symptomatic patients in health care facilities should be placed and treated under an appropriate quarantine. 
Although most patients respond well to the discontinuation of antibiotics and administration of oral metronidazole or vancomycin, $20 \%-30 \%$ of patients experience recurrence. ${ }^{4}$ Therefore, the management of recurrent CDI is often challenging, given the infection control aspect, combined with the increase in the related morbidity, mortality, and health care expenditures. ${ }^{5-9}$ Several studies have reported that various risk factors are associated with recurrence, including advanced age, concurrent use of antibiotics, chronic renal insufficiency, elevated white blood cell counts, low serum albumin levels, gastric and acid anti-secretory medications, and prolonged hospitalization. ${ }^{10-14}$

Despite the increasing awareness of CDI, an appropriate surveillance methodology has not been established in Japan, and very few Japanese studies have surveyed the prevalence of CDI using standard surveillance definitions. One exception is a study that investigated the incidence rate of health care facility-onset CDI (HO-CDI) in a Japanese tertiary care center. ${ }^{15}$ Therefore, the currently available information is insufficient to indicate an appropriate clinical practice, and the collected data are of little practical use. Furthermore, it is important to identify the risk factors for recurrent CDI, as these can be used to develop early preventative measures and therapeutic interventions.

Given these limitations in our knowledge of recurrent CDI, this study's first purpose was to investigate current status of CDI in health care settings using standard surveillance definitions. ${ }^{3}$ The second purpose was to identify the risk factors that were associated with recurrence in a Japanese health care facility.

\section{Materials and methods \\ Target patients}

This retrospective study was carried out between August 2011 and September 2013, at the Tokyo Women's Medical University Hospital (TWMUH), which is a 1,423-bed teaching hospital. Medical records were used to collect all clinical data, including demographic information, comorbidities, medications (immunosuppressive agents, chemotherapies, and gastric acid suppressions), laboratory test results, severity of the CDI (defined as leukocytosis with a white blood cell count of $15,000 / \mu \mathrm{L}$ or higher or a serum creatinine level greater than or equal to 1.5 times the premorbid level), initial medication that was prescribed for the CDI (oral metronidazole or vancomycin), and clinical outcomes. CDI cases were defined based on the Society for Healthcare Epidemiology of America (SHEA) and the Infection Diseases Society of America (IDSA) guideline, as diarrheal patients with stool samples that were positive for $\mathrm{CD}$ toxin, ${ }^{3}$ as detected via enzyme immunoassay (EIA) (C. DIFF QUIK CHEK COMPLETE ${ }^{\circledR}$ test, Alere, Tokyo, Japan).

All hospitalized patients who were $>2$ years old were considered eligible. We categorized the timeline for case definition according to the SHEA/IDSA guideline ${ }^{3}$ and our inclusion criteria for HO-CDI cases were either 1) patients who had developed CDI hospitalized for more than 3 days or 2) patients who had developed CDI within 48 hours of admission to TWMUH with history of admission in health care facilities in previous 12 weeks. However, patients who were diagnosed with CDI within 48 hours after admission to TWMUH and had no history of hospitalization in the previous 12 weeks were classified as having community-acquired CDI. Patients with community-acquired CDI and patients who were only positive for glutamate dehydrogenase were excluded from our analysis.

Recurrent CDI was defined as a subsequent episode of CDI within 8 weeks from the previous episode, and its diagnosis was based on the same criteria as the first episode of CDI. Patients with recurrence after their discharge were excluded from our analysis. We grouped the patients into recurrent and non-recurrent groups, and investigated the risk factors that were associated with recurrence.

\section{Statistical analysis}

To identify the factors that were associated with CDI recurrence, categorical variables were evaluated using Fisher's exact test, while continuous independent variables were evaluated using the Mann-Whitney $U$ test. A two-sided $P$-value of $<0.05$ was considered to be statistically significant, and variables were subsequently used in the multivariate logistic regression model. All analyses were performed using R 3.0.2 software (The R Foundation for Statistical Computing Platform).

\section{Ethical consideration}

This study was approved by the Ethics Committee of the TWMUH.

\section{Results}

\section{Patients and background}

During the 26-month study period, 2,193 specimens from inpatients and outpatients were tested for CD toxin, and 107 specimens were found to be positive for CD toxin. Seventy-six hospitalized patients were diagnosed with HO-CDI, with an incidence rate of 0.8 cases per 10,000 patient-days (Figure 1). 


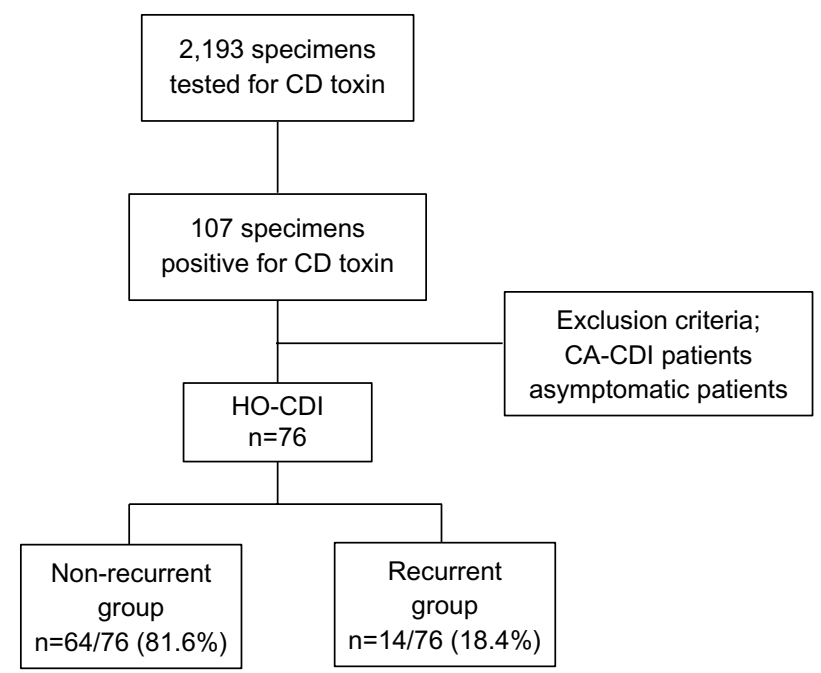

Figure I Patient disposition.

Abbreviations: $\mathrm{CD}$, Clostridium difficile; $\mathrm{HO}-\mathrm{CDI}$, health care facility-onset Clostridium difficile infection; CA-CDI, community-acquired Clostridium difficile infection.

Among the cases of HO-CDI, the median patient age was 69.5 years (range, $2-95$ years), and 50 patients $(65.8 \%)$ were $>65$ years old (Table 1$)$. Thirty-nine patients $(51.3 \%)$ were men and 37 (48.7\%) were women. The median duration of hospitalization before the diagnosis of CDI was 28 days (range, $1-155$ days). Forty-one patients (53.9\%) had malignant disease, 24 patients $(31.6 \%)$ had heart disease, eleven patients (14.5\%) had gastrointestinal disease, and four patients $(5.3 \%)$ had received a transplant. Among the 41 patients with malignant disease, ten patients had gastrointestinal tumors and eight patients had hematological tumors.

All the enrolled patients had diarrhea, but none of them had ileus or toxic megacolon. The mean temperature was 37.1 Celsius (range, 35.9-41.2) and 13 patients (17.1\%) had fever with temperature of 38.0 Celsius or over.

To treat the CDI, 49 patients (64.5\%) received oral metronidazole and 27 (35.5\%) received oral vancomycin, with a median treatment duration of 14 days (range, 6-52 days). Fourteen cases of CDI (18.4\%) were recurrent, which included 13 patients who had experienced single recurrent episode and one patient who had experienced three recurrent episodes. Six patients $(7.9 \%)$ were categorized as having severe CDI, per the SHEA/IDSA guideline. ${ }^{3}$ The 30 -day mortality rate was $7.9 \%(n=6)$ and the 90 -day mortality rate was $14.5 \%$ $(n=11)$; none of these deaths were related to CDI.

\section{Risk factors for recurrent CDI}

Among the 76 patients with HO-CDI, 14 patients (18.4\%) were included in the recurrent group and the remaining
Table I Demographic and clinical characteristics of the patients with HO-CDI

\begin{tabular}{|c|c|}
\hline Variables & n (\%) \\
\hline Age; mean (range) & $69.5(2-95)$ \\
\hline Age $\geq 65 \mathrm{yr}$ & $50(65.8)$ \\
\hline Sex, male & $39(51.3)$ \\
\hline \multicolumn{2}{|l|}{ Underlying disease } \\
\hline Malignant disease & $4 \mid(5.3)$ \\
\hline Heart disease & $24(31.6)$ \\
\hline Gastrointestinal disease & II (I4.5) \\
\hline Transplantation & $4(5.3)$ \\
\hline \multicolumn{2}{|l|}{ Medication } \\
\hline Immunosuppressive agents & $18(23.7)$ \\
\hline Chemotherapy & $20(26.3)$ \\
\hline \multicolumn{2}{|l|}{ Gastric acid suppression } \\
\hline Histamine $\mathrm{H} 2$ blockers & $13(17.1)$ \\
\hline Proton pump inhibitors & $47(61.8)$ \\
\hline \multicolumn{2}{|l|}{ Clinical parameters } \\
\hline Temperature (Celsius); mean (range) & $37.1(35.9-41.2)$ \\
\hline Temperature $\geq 38$ Celsius & $13(17.1)$ \\
\hline $\begin{array}{l}\text { Peripheral white blood cell count }(/ \mu \mathrm{L}) \text {; } \\
\text { mean (range) }\end{array}$ & $6,505(70-43,660)$ \\
\hline Serum albumin ( $g / d L) ;$ mean (range) & $2.6(1.9-4.7)$ \\
\hline Serum CRP (mg/dL); mean (range) & $4.1(0.04-24.3)$ \\
\hline $\begin{array}{l}\text { Duration from admission to diagnosis, } \\
\text { days; mean (range) }\end{array}$ & $28(I-55)$ \\
\hline ICU admission & $3(3.9)$ \\
\hline Recurrent CDI & $14(18.4)$ \\
\hline Severe CDI & $6(7.9)$ \\
\hline \multicolumn{2}{|l|}{ Medication for CDI } \\
\hline Metronidazole & $49(64.5)$ \\
\hline Vancomycin & $28(36.8)$ \\
\hline $\begin{array}{l}\text { Treatment duration for CDI, days; mean } \\
\text { (range) }\end{array}$ & $14(6-52)$ \\
\hline 30 days mortality & $6(7.9)$ \\
\hline 90 days mortality & II (I4.5) \\
\hline
\end{tabular}

Abbreviations: $\mathrm{HO}-\mathrm{CDI}$, health care facility-onset Clostridium difficile infection; $\mathrm{ICU}$, intensive care unit; $y r$, years.

62 patients $(81.6 \%)$ were included in the non-recurrent group. However, none of the factors that we examined were statistically significant in the univariate analysis (Table 2). In contrast, the multivariate analysis revealed that the recurrent group had significant underlying malignant disease (odds ratio: $7.98 ; 95 \%$ confidence interval: $1.22-52.2 ; P=0.03$ ) and were more likely to be hospitalized in the intensive care unit (ICU) (odds ratio: 49.9; 95\% confidence interval: 1.01-2470; $P=0.049)$.

\section{Discussion}

Incidence rate of $\mathrm{HO}-\mathrm{CDI}$ in Europe has been reported at 4.1 cases per 10,000 patient-days, ${ }^{16}$ which is lower than the American incidence rate of $7.8^{17}$ and the Canadian incidence rate of $6.5 .{ }^{18}$ However, only a few epidemiological surveys have examined Asian populations. Among these studies, 
Table 2 Univariate and multivariate analysis of risk factors for recurrent CDI

\begin{tabular}{|c|c|c|c|c|}
\hline Variables & $\begin{array}{l}\text { Recurrent group } \\
(\mathrm{N}=14)\end{array}$ & $\begin{array}{l}\text { Non-recurrent group } \\
(\mathrm{N}=62)\end{array}$ & $P$-value & $\begin{array}{l}\text { Multivariate analysis } \\
\text { OR }(95 \% \mathrm{Cl}), P \text {-value }\end{array}$ \\
\hline Age; mean (range) & $69(3 I-86)$ & $69.5(2-95)$ & 0.33 & \\
\hline Age $\geq 65 \mathrm{yr}$ & $9(64.3)$ & $4 I(66.1)$ & I & \\
\hline Sex, male & $6(42.9)$ & $33(53.2)$ & 0.56 & \\
\hline \multicolumn{5}{|l|}{ Underlying disease } \\
\hline Malignant disease & $9(64.3)$ & $32(51.6)$ & 0.55 & $7.98(1.22-52.2), 0.03$ \\
\hline Heart disease & $6(42.9)$ & $18(29.0)$ & 0.35 & \\
\hline Gastrointestinal disease & $3(21.4)$ & $8(12.9)$ & 0.41 & \\
\hline Transplantation & I (7.I) & $3(4.8)$ & 0.57 & \\
\hline \multicolumn{5}{|l|}{ Medication } \\
\hline Immunosuppressive agents & $4(28.6)$ & $14(22.6)$ & 0.73 & \\
\hline Chemotherapy & $4(28.6)$ & $16(25.8)$ & I & \\
\hline \multicolumn{5}{|l|}{ Gastric acid suppression } \\
\hline Histamine $\mathrm{H} 2$ blockers & $4(28.6)$ & $9(14.5)$ & 0.24 & \\
\hline Proton pump inhibitors & $8(57.1)$ & $39(62.9)$ & 0.76 & \\
\hline \multicolumn{5}{|l|}{ Clinical parameters } \\
\hline $\begin{array}{l}\text { Temperature (Celcius); mean } \\
\text { (range) }\end{array}$ & $36.9(35.9-37.8)$ & $37.1(36.2-41.2)$ & 0.11 & \\
\hline $\begin{array}{l}\text { Peripheral white blood cell } \\
\text { count }(/ \mu \mathrm{L}) \text {; mean (range) }\end{array}$ & $7,020(260-16,450)$ & $6,315(70-43,660)$ & 0.66 & \\
\hline Serum albumin ( $g / d L) ;$ mean (range) & $2.4(1.9-3.7)$ & $2.6(1.9-4.7)$ & 0.28 & \\
\hline Serum CRP (mg/dL); mean (range) & $5.1(0.04-10.3)$ & $3.87(0.13-24.3)$ & 0.88 & \\
\hline $\begin{array}{l}\text { Durataion from admission to } \\
\text { diagnosis, days; mean (range) }\end{array}$ & $31.5(I-\mid I 2)$ & $27.5(I-155)$ & 0.68 & \\
\hline ICU admission & $2(14.3)$ & $\mathrm{I}(\mathrm{I} .6)$ & 0.085 & 49.9 (I.0I-2,470), 0.049 \\
\hline Severe CDI & I (7.I) & $5(8.1)$ & I & \\
\hline \multicolumn{5}{|l|}{ Medication for CDI } \\
\hline Metronidazole & $9(64.3)$ & $40(64.5)$ & I & \\
\hline Vancomycin & $5(35.7)$ & $22(37.1)$ & I & \\
\hline $\begin{array}{l}\text { Treatment duration for CDI, days; mean } \\
\text { (range) }\end{array}$ & $14(10-24)$ & $12(6-52)$ & 0.88 & \\
\hline 30 days mortality & I (7.I) & $5(8.1)$ & 1 & \\
\hline 90 days mortality & $3(2 I .4)$ & $8(12.9)$ & 0.41 & \\
\hline
\end{tabular}

Abbreviations: $\mathrm{CDI}$, Clostridium difficile infection; $\mathrm{Cl}$, confidence interval; OR, odds ratio; yr, years; ICU, intensive care unit.

Korea's reported incidence rate was $7.16,{ }^{19}$ Taiwan's was $4.5,{ }^{20}$ Singapore's was $2.99,{ }^{21}$ and a Japanese survey reported an incidence rate of 3.11 cases per 10,000 patient-days. ${ }^{15}$ In our study, the HO-CDI incidence rate was 0.8 cases per 10,000 patient-days, and this rate is noticeably lower than those reported in Europe, the US, and other Asian countries. Although EIA detection of CD toxin is rapid, convenient and low-cost (compared to other diagnostic testing methods), the EIA method has been reported to have limited sensitivity and/or specificity. In addition, diagnosis with low sensitivity testing alone could misdiagnose some CDI cases; therefore, changes in the laboratory methods that are used may lead to a higher reported incidence rate. Unfortunately, in Japan, the EIA method is the only commercially available method for CD toxin detection; therefore, diagnoses that were made using only the low sensitivity test may have affected our observed incidence rate. Furthermore, recent data from the US indicate that $\mathrm{a} \geq 30 \%$ increase in the incidence of CDI may be observed after the adoption of more sensitive nucleic acid amplification tests. ${ }^{22}$ Therefore, the CDI incidence rate might be underestimated in Japan, as not all diarrheal patients are routinely evaluated; greater awareness and improved surveillance may increase the number of reported CDI cases. Finally, there might also be differences in the CD toxicity that may have influenced our patients' sensitivity to infection as well as CDI-related mortality, as the CDI incidence and mortality varies depending on time and location. For example, there has been a well-documented increase in the incidence of CDI in the US and European countries, which is largely attributed to the spread of the ribotype 027 strains. $^{23,24}$

In our study, the recurrence rate for HO-CDI was $18.4 \%$, and ICU stay and malignant diseases were the only significant risk factors that were associated with recurrence. In contrast, previous studies have identified various predictors of recurrent CDI, including advanced age, concurrent use of antibiotics, chronic renal insufficiency, elevated white 
blood cell count, low serum albumin level, gastric and acid anti-secretory medications, and prolonged hospitalization. ${ }^{10-14}$ Although these factors did not reach statistical significance in our study, it is possible that those previously known risk factors could have coexisted in extended ICU stay and malignant disease. Similar to our results, Salva et al have reported that ICU patients have a higher recurrence rate and risk of recurrence, which were associated with a prolonged ICU stay. ${ }^{25}$ Furthermore, ICU patients experience multiple antibiotic exposures, due to a high number of nosocomial infections, which include ventilator-associated infections, catheter-related urinary tract infections, and catheter-related bloodstream infections. Patients with malignant diseases are also at risk for acquiring CDI, due to their immunosuppressive state, exposure to broad-spectrum antibiotic treatment and/or chemotherapies. In addition, several chemotherapeutic agents are associated with development of CDI. ${ }^{26}$ Patients who are undergoing stem cell transplantation are also susceptible to CDI and substantial gastrointestinal damage, due to their conditioning regimens and radiation, graft-versus-host disease in the gastrointestinal tract and prolonged neutropenic state. ${ }^{27}$ Therefore, the severity of their underlying medical condition and low nutritional state, combined with their disrupted gastrointestinal environment (due to antibiotic, chemotherapy, and radiation therapy), could lead to a higher incidence, recurrence, and complication rate for CDI.

This study has several limitations. First, this was a singlecenter study with a relatively small number of patients. Although this is one of the few studies to provide recent data regarding the status of CDI in Japan, the data may not generalize to other Japanese hospitals; therefore, additional studies should be conducted in different settings. Second, the retrospective design may have led to an under-diagnosis of CDI cases, and molecular typing was not performed. Since the 1990s, a hypervirulent CD strain has become common in the US and several European countries, and it is associated with a significant risk of recurrence. ${ }^{28,29}$ As our diagnosis was only based on EIA detection of CD toxin, comparison of our data with those from previous studies (which used more sensitive tests) may lead to misinterpretation of our results. In addition, discharged patients were not under close follow-up, which may have led to underestimated recurrent cases.

In conclusion, our study is one of the few surveys to report the current incidence of CDI in Japan, and was the first study to investigate cases of recurrent CDI. Based on our results, ICU hospitalization and malignancy were significant risk factors for recurrence. Therefore, patients with malignancy and history of ICU hospitalization should be closely monitored for recurrence, and appropriate antimicrobial stewardship is needed to reduce CDI recurrence. However, both ICU hospitalization and malignancy are potentially under immunocompromised situation and would be highly challenging to put appropriate antimicrobial stewardship. Further studies are needed to assess the comprehensive features of CDI, as well as the prevalence of recurrent cases in Japan.

\section{Disclosure}

The authors have no conflicts of interest to disclose.

\section{References}

1. Kelly CP, Pothoulakis C, LaMont JT. Clostridium difficile colitis. $N$ Eng $J$ Med. 1994;330(4):257-262.

2. Lamontagne F, Labbé AC, Haeck O, et al. Impact of emergency colectomy on survival of patients with fulminant Clostridium difficile colitis during an epidemic caused by a hypervirulent strain. Ann Surg. 2007;245(2):267-272.

3. Cohen SH, Gerding DN, Johnson S, et al. Clinical practice guidelines for Clostridium difficile infection in adults: 2010 update by the Society for Healthcare Epidemiology of America (SHEA) and the Infectious Diseases Society of America (IDSA). Infect Control Hosp Epidemiol. 2010;31(5):431-455.

4. Vardakas KZ, Polyzos KA, Patouni K, Rafailidis PI, Samonis G, Falagas ME. Treatment failure and recurrence of Clostridium difficile infection following treatment with vancomycin or metronidazole: a systematic review of the evidence. Int J Antimicrob Agents. 2012;40(1):1-8.

5. Dubberke ER, Olsen MA. Burden of Clostridium difficile on the healthcare system. Clin Infect Dis. 2012;55 Suppl 2:S88-S92.

6. Ghantoji SS, Sail K, Lairson DR, DuPont HL, Garey KW. Economic healthcare costs of Clostridium difficile infection: a systematic review. J Hosp Infect. 2010;74(4):309-318.

7. Hookman P, Barkin JS. Clostridium difficile associated infection, diarrhea and colitis. World J Gastroenterol. 2009;15(13):1554-1580.

8. Karas JA, Enoch DA, Aliyu SH. A review of mortality due to Clostridium difficile infection. J Infect. 2010;61(1):1-8.

9. Rupnik M, Wilcox MH, Gerding DN. Clostridium difficile infection: new developments in epidemiology and pathogenesis. Nat Rev Microbiol. 2009;7(7):526-536.

10. Garey KW, Sethi S, Yadav Y, DuPont HL. Meta-analysis to assess risk factors for recurrent Clostridium difficile infection. J Hosp Infect. 2008;70(4):298-304.

11. Fekety R, McFarland LV, Surawicz CM, Greenberg RN, Elmer GW, Mulligan ME. Recurrent Clostridium difficile diarrhea: characteristics of and risk factors for patients enrolled in a prospective, randomized, double-blinded trial. Clin Infect Dis. 1997;24(3):324-333.

12. McFarland LV, Surawicz CM, Rubin M, Fekety R, Elmer GW, Greenberg RN. Recurrent Clostridium difficile: epidemiology and clinical characteristics. Infect Control Hosp Epidemiol. 1999;20(1):43-50.

13. Cadle RM, Mansouri MD, Logan N, Kudva DR, Musher DM. Association of proton-pump inhibitors with outcomes in Clostridium difficile colitis. Am J Health Syst Pharm. 2007;64(22):2359-2363.

14. Kim JW, Lee KL, Jeong JB, et al. Proton pump inhibitors as a risk factor for recurrence of Clostridium-difficile-associated diarrhea. World J Gastroenterol. 2010;16(26):3573-3577.

15. Honda H, Yamazaki A, Sato Y, Dubberke ER. Incidence and mortality associated with Clostridium difficile infection at a Japanese tertiary care center. Anaerobe. 2014;25:5-10.

16. Bauer MP, Notemans DW, van Benthem BH, et al. Clostridium difficile infection in Europe: a hospital-based survey. Lancet. 2011;377(9759): $63-73$. 
17. Benoit SR, McDonald LC, English R, Tokars. Automated surveillance of Clostridium difficile infections using BioSense. Infect Control Hosp Epidemiol. 2011;32(1):26-33.

18. Gravel D, Miller M, Simor A, et al. Health care-associated Clostridium difficile infection in adults admitted to acute care hospitals in Canada: a Canadian Nosocomial Infection Surveillance Program Study. Clin Infect Dis. 2009;48(5):568-576.

19. Kim J, Kang JO, Kim H, et al. Epidemiology of Clostridium difficile infections in a tertiary-care hospital in Korea. Clin Microbiol Infect. 2013;19(6):512-517.

20. Lee YC, Wang JT, Chen AC, Sheng WH, Chang SC, Chen YC. Changing incidence and clinical manifestations of Clostridium difficile-associated diarrhea detected by combination of glutamate dehydrogenase and toxin assay in Northern Taiwan. J Microbiol Immunol Infect. 2012;45(4): 287-295.

21. Hsu LY, Tan TY, Koh TH, et al. Decline in Clostridium difficile-associated disease rates in Singapore public hospitals, 2006 to 2008. BMC Res Notes. 2011;4:77.

22. Gould CV, Edwards JR, Cohen J, et al. Effect of nucleic acid amplification testing on population-based incidence rates of Clostridium difficile infection. Clin Infect Dis. 2013;57(9):1304-1307.
23. Freeman J, Bauer MP, Baines SD, et al. The changing epidemiology of Clostridium difficile infections. Clin Microbiol Rev. 2010;23(3): 529-549.

24. McDonald LC, Kilgore GE, Thompson A, et al. An epidemic, toxin gene-variant strain of Clostridium difficile. NEngl JMed. 2005;353(23): 2433-2441.

25. Salva S, Duran N, Rodriguez V, et al. Clostridium difficile in the ICU: study of the incidence, recurrence, clinical characteristics and complications in a university hospital. Med Intensiva. 2014;38(3):140-145.

26. Chopra T, Alangaden GJ, Chandrasekar P. Clostridium difficile infection in cancer patients and hematopoietic stem cell transplant recipients. Expert Rec Anti Infect Ther. 2010;8(10):1113-1119.

27. Alonso CD, Treadway SB, Hanna DB, et al. Epidemiology and outcomes of Clostridium difficile infections in hematopoietic stem cell transplant recipients. Clin Infect Dis. 2012;54(8):1053-1063.

28. Petrella LA, Sambol SP, Cheknis A, et al. Decreased cure and increased recurrence rates for Clostridium difficile infection caused by the epidemic C. difficile BI strain. Clin Infect Dis. 2012;55(3):351-357.

29. Marsh JW, Arora R, Schlackman JL, Shutt KA, Curry SR, Harrison LH. Association of relapse of Clostridium difficile disease with BI/NAP/027. J Clin Microbiol. 2012;50(12):4078-4082.

\section{Publish your work in this journal}

Clinical and Experimental Gastroenterology is an international, peerreviewed, open access journal, publishing all aspects of gastroenterology in the clinic and laboratory, including: Pathology, pathophysiology of gastrointestinal disease; Investigation and treatment of gastointestinal disease; Pharmacology of drugs used in the alimentary tract;
Immunology/genetics/genomics related to gastrointestinal disease. This journal is indexed on CAS. The manuscript management system is completely online and includes a very quick and fair peer-review system. Visit http://www.dovepress.com/testimonials.php to read rea quotes from published authors. 